\title{
DIFFERENT SCHOOLS AS NARRATIVE COMMUNITIES. IDENTITY NARRATIVES IN THREEFOLD
}

\author{
Ina ter Avest*, Cok Bakker** \& Siebren Miedema* \\ *Vrije Universiteit Amsterdam \& **Utrecht \\ University
}

\begin{abstract}
The last decade identity is often and very fruitfully conceptualized as 'narrative identity'. Neither for individuals nor for groups identity is a given beforehand anymore. On the contrary, identity has to be constructed in an inductive way. Three qualitative research methods are applied to explore in an inductive way the school's narrative identity, combining the individual and the group processes of narrative identity construction. Our data reveal a close relationship between autobiographical critical incidents in teacher's and principal's commitment to the school's identity. However, still more research is needed in particular in the field of affective relationships establishing mutual relations between autobiographical identity and institutional identity.
\end{abstract}

\section{INTRODUCTION}

In the story that I tell about myself I reveal where I come from, who I am and what my dreams are. This self-narrative can be seen as a process of identity construction. It is nowadays considered to be a never-ending story, since in modern times identity is no longer seen as to be obtained by birth, but has to be acquired in a lifelong process of construction and recognition (Taylor 1989; 1991). Identity is conceptualized as 'narrative identity' that is identity-by-story-telling. Each person has to tell her/his own story. Neither for individuals nor for groups and institutions identity is perceived as being given in a top-down deductive way, for example on the base of kinship. The net result is that identity has to be constructed in an bottom-up inductive way. Just 
like individuals, groups and institutions have to elaborate on their identity by telling their story, 'as it is in my view' (Schein 2001). In schools the individual and the institutional process of identity construction come together.

In this contribution we introduce three qualitative research methods to explore in an inductive way the school's narrative identity. We combine here the individual and the group processes of narrative identity construction. In section one we describe the Dutch educational context and its recent changes, being the horizon against which our threefold qualitative research project is outlined. In section two we describe the theoretical framework of narrative identity. In the third section identity construction at the level of the school management is presented. As part of an inservice training, directors and/or assistantdirectors articulated their narratives on the characteristic aspects of their school. Section four will deal with the interviews of directors and/or assistant-directors, following the procedure of the Self Confrontation Method. Section five describes the exploration of narratives of teachers on 'examples of good practice', presenting a valid picture of the school's identity. In the last, discussion and recommendations section we reflect on the results and formulate some recommendations for further research.

\section{THE DUTCH EDUCATIONAL CONTEXT}

At the beginning of the 20th century, the Netherlands gave a picture of a static monocultural society. What seemed to be a homogeneous culture at first glance, on closer inspection requires a more shaded description. On the one hand Dutch society was homogeneous in the field of ethnicity, and on the other hand a certain degree of heterogeneity was discernible as several (sub-)cultures existed alongside each other. The concept of 'pillarization' is coined to describe and to cope with the heterogeneity within a monocultural society. The 'pillars' distinguished themselves mainly by difference in religious affiliation.

During the second half of the last century the monocultural homogeneous and 'pillarized' society has been transformed into a multicultural and 
multireligious society. The arrival of 'guest workers' in the sixties already changed the scene, but the reunion with their families, starting in the eighties of the last century and their permanent stay, had a decisive influence on the Dutch culture. The confrontation with the otherness of the guest workers and their other religion, the Islam, articulated the religious plurality within Dutch society.

In Europe, at the beginning of the twenty-first century, the Netherlands together with Estonia and the Tsjech Republic belong to the most secularized countries. However, the Dutch educational system (in contrast to the actual situation in schools) is still 'pillarized' in nature based on denomination. So formally speaking, education is based on religious dividing lines. As a consequence there is denominational education in for example Protestant and Roman Catholic schools and just a few Jewish schools. Protestant and Roman Catholic schools each count for about 60 of the primary schools (fully financed by the government), public schools account for only $30 \%$, the rest being private schools, providing education from a specific religious background or a specific pedagogical or philosophical concept. In the last decade of the twentieth century the new 'pillar' of the Islamic schools has been added to the system, with some forty schools counting for less than 1\% of the total number of schools. Behind this formal picture, we distinguish that within each 'pillar' every school has its own culture, related to its 'well-considered convictions' such as implicit or explicit opinions about 'the good life', the ideal person, the ideal child, the good society and what the transcendental or God is like. All this shapes the instruction that is offered, and gives direction to the activities of the members of the school community, be it managing activities, teaching activities or a variety of supportive activities.

School mirroring society, the plurality of the population of the Netherlands, logically results in a plurality in the school's population. Yet even within schools with a distinctive identity the school culture often is heterogeneous. School identity is composed of the typical characteristics constituting the daily practices. One of the 'typical characteristics' of Christian schools is that they organize education according to the ideas of 'the good life' as they are narrated and valued 
against the horizon of the Christian religious tradition. These schools substantiate those ideas of the 'good life' in different aspects of identity: school assemblies as well as the choice of teaching methods.

In Protestant and Catholic schools, as well as in public schools indigenous pupils are a minority of the primary schools, the so called 'black schools'. It is in these predominantly 'black' schools, having a formal Christian identity (which in earlier days shaped their daily activities), with a mixed population of a minority of indigenous and a majority of immigrant children, that the question is raised: 'How to practice the Christian identity of the school, when the individual child in most cases is socialized in a different religious tradition?'. The interrelatedness of a religious background with also differing ethnical, national and cultural backgrounds complicates the answer to this crucial question. To provide a help to answer this type of questions three research methods were developed within the theoretical framework of narrative identity. In the next sections we will first present the theoretical framework.

THEORETICAL FRAMEWORK: NARRATIVE IDENTITY

For a long time the concept of identity was only applied to individuals and in a particular way. Identity was seen as an end stage in the development from childhood to adolescence. In pedagogy it was connotated as a development from a situation of complete dependency to a more or less clear-cut status of independency in the sense of a competency of a person to accept responsibility for and give account of its opinions and behavior in accordance with the highest standards of one's own conviction (Langeveld 1967). In developmental psychology identity was conceptualized as a product, coming into existence in a preceding process (Breeuwsma 1993; 1999). Puberty was then seen as a pivotal period in the process of identity development. During this process, starting in early childhood and continuing in puberty, a lot of movement, growth and development could be noticed. During puberty identity was completed in its permanent form. And when the person's identity development resulted in its definitive form, hardly 
any change would occur anymore. Puberty is seen as a phase of 'Sturm und Drang'. In this phase the young adolescent is offered enough chances to experiment with possible identities (Bosma \& Graafsma 1982). In changing contexts the adult is the end product of a turbulent period, though not the same person, he is similar to himself in other times and places. This conception of identity was also foundational for the conception of religious identity.

In the public and academic debate the clearcut status of identity has been subject of profound debate, making notice of the change of view of the concept of development, as well as the change of the position of adolescents in our society. Not identity as an end product, but far more identity development as a dynamic process in a particular contxet, is currently the focus in theory formation and empirical research on life span development. Identity is seen here as a 'never ending story', and as an activity. In the encounter with others the person get to know her/himself, in every encounter an other aspect. Telling about what happens in these encounters in narratives grant insight and validates what the person knows about itself and makes this communicable to others. In the narrative the person is known. In the story that is told and retold the person constructs its identity (Freeman 1991). This is called a narrative identity. In the concept of the narrative identity the competence of the person is stressed "to comprehend a complex flow of action and to act appropriately within it. (...) It is the very process we use to understand the social life around us and our own position in this process" (Carrithers 1992, 78). With the concept of narrativity Carrithers is not focusing on story telling as such, but on comprehending and understanding complex relationships between actions and attitudes. In the narrative approach an action is not the result of a stimulus, but an action is situated within the framework of a larger unity. Every action in the narrative approach is part of an unfolding story. This narrative process takes a life span. In other words: identity is not so much a construct, but a constructing process. Lifespan psychology focuses on the relationship between the identity of the person and the commitments of the person to for example a partner, a religious community, a profession or a political party. 
Instead of identity as an final stage of development to be achieved, the concept of identity covers the life-long process of becoming who you are. Identity is influenced by 'significant others', marked by 'critical incidents', constructed in telling and re-telling stories connecting meaningful events, resulting in what is called a 'narrative identity'. Bruner has applied this concept to educational contexts (Bruner 1996). Along this theoretical lines every person can be characterized and identified as being 'a living document' (Luther 1992).

However, the concept of identity is not only applicable to persons. Scholars in organizational theory also make use of the concept, distinguishing between a fixed identity and the process of identity development. In the area of organizations the concept of 'culture' has been more frequently used than the concept of 'identity', though the definitions of the terms used show similarities (see for example Morgan 1992, Schein 2000, De Wolff, 2000). Within this framework also the concept of 'corporate identity' is frequently used to point to the identity of an institution. The encounter with different cultures in creating a communal organizational culture has extensively been researched by Hofstede (2002).

With the concept of identity we describe the features of the institution as they are noticed by people as well as the process by which the institutional, for example a school's identity is constructed. De Wolff gave the following definition of a school's identity: "the identity of a school is what makes a school into this school, or what are the peculiar characteristics of this school (both in a characteristic and a distinguishing sense) and what the members of the school have in common, what they share, what is true for them as members of the collective community and what could be characterized by a certain degree of durability and continuity" (De Wolff 2000, 53; De Wolff, De Ruyter \& Miedema 2003).

It should be stressed at this point that in the process of identity development in an organization, be it a factory, an office or a school, the contribution of every participant is considered to be of pivotal significance. The way in which employees behave in their daily professional activities present to outsiders the atmosphere of an organization, gives them an 
impression of the climate in the organization, in other words it shows them aspects of the company or institution which reveals the identity of that particular organization. The employee in the first place acts as a professional, a kind of behavior that is imbued with personal values of course. On the basis of an accidental combination of the type of single impressions of the individual professionalism of the employees, outsiders construct their image of the organization. This leads to a focus on the individual's professionalism, in particular to the normative dimension as it is related to the biography.

\section{SCHOOL MANAGEMENT}

The school's identity can be described as something fixed and decided upon by others: school governors and school boards and 'powerful identity documents', prescribing in deductively the ways in which this formal identity had to be concretized in daily rituals like morning prayer, telling Bible stories and celebrating religious (mainly Christian) feasts. However, observing the classroom activities, diversity seemed to be the standard in the implementation of the rather detailed specifications of the realization of the school's Christian identity.

We notice quite often here the lack of a relationship between the formal school identity as it is described in school documents and school guides, and the way directors and/or assistant directors perceive the practical identity in the classroom. A certain influence from or at least a related and dependant relationship with the personalities of the teachers should in our view not be denied, in particular a relationship with their subjective valuations and classroom regulations. In this respect, concrete teacher behavior constitutes the school's identity not in the way as it is explicitly written down, like for example in formal and official school documents, but as it is perceived by the pupils and their parents, informally, as a lived identity. Life view is motivating the actions of the teacher and at the same time life view shows itself in his or her pedagogical and didactical actions.

It is striking here that there is a similarity between the way we can describe the identity of 
persons and the identity of institutions, like schools. As was said earlier, identity refers to outer public features as well as to the inner construction processes. In the identity of a person as well as in the identity of an institution past, present and future are linked. Over the past few years there has been an increasing interest not only in the analogy of these processes but even more so in their mutual influences. Not only a relationship of the school's identity with the personality of the teacher urge itself upon us, even more so the influence of the interaction between teachers among themselves on the topic of school identity, and to a still larger extent the interaction with the articulated views of the management on the characteristic aspects of their school which we extensively explored with the help of our first research method.

We dealt in this research approach with 374 participating directors of elementary schools. We gave them a conceptual toolbox to use for reflection with their team members on their theoretical stance in respect with identity and plurality. It enabled them also to reflect on their practices, that is on concrete educational situations and relations in their schools and to construct their narratives.

We just want to pay attention here to one interesting outcome in respect with the impact of the formal identity. The reflective processes the principals got through mirror a growing understanding of the idea that identity has to do with everything that is going on in the school'. An interesting ambiguous position is evoked from this view concerning the formal identity of the school. Very often this is a Christian identity, be one in explicit differing shades and colours, sometimes it is a 'neutral', Muslim, Hindu or different formally described identity of the school. On the one hand principals practise the integrated reflection on identity which makes the formal identity more relative. They discover that it is too simple to keep on living with the idea that a deductive perception of Christian school identity produces homogenous Christian schools. The same foundations of Christian schools can lead to the development of different school practices, because for example different pedagogical choices are made at the same time. On the other hand, we observe that very often the formal fact that the school is a Christian 
school 'triggers' the reflection on identity and is in many cases the immediate cause for identity deliberation in the team. Although one knows that much more is relevant, identity deliberation is evoked almost self-evidently from 'only' the given formal identity of the school. Many examples rise from the narrative data, like teachers that claim that it would make no sense to appoint a Muslimteacher at the Christian school, or parents starting to argue that some children literature should not be allowed and read in a real Christian (see extensively Bakker \& Miedema 2006).

\section{IDENTITY DEVELOPMENT IN CONTEXT}

In the concept of narrative identity as a process the relationship with the context is always included. The second method of exploration in our triangulate research project is explicitly focusing on this contextual aspect of identity development. We explore the mutual relationship between the personal and professional identity development of the principal and/or assistant-principal and the school's identity. In what way does the story of the principal relate to the telling and re-telling of the story of the school?

In telling the life story the person relates 'critical' events and situations to each other in order to arrive at a comprehensive life story. The events are like beads threaded on the string of the life story. However, the beads may be threaded in various ways, selecting them according to their color, their shape or an other characteristic. In the same way, by telling and retelling her/his life story the person selects the 'critical incidents' according to the way things are in her/his view at thas very moment. The implicit or explicit selection criteria in telling the life story show the life theme of that person. It is on this life theme and its relation to the identity of the school that our research method is focusing.

To explore this relationship we make use of a particular dialogical interviewing technique, the so called Self Confrontation Method (SCM). This dialogical interviewing technique, developed within the Valuation Theory (VT) of the Dutch psychologist Hermans (Hermans \& Hermans-Jansen, 1995), harmonizes with the narrative approach of identity development. Central to Hermans' VT is the person 
as a 'motivated storyteller'. Hermans states that people's behavior is always, either conscious or pre-conscious, intentional behavior. In some way or another behavior is always motivated either by a need to establish one's own strength or by the commitment to others. In Hermans' terminology people are motivated by the S-motive or the Omotive. Dependent upon the context, the $S-$ or the O-motive appears to be dominant in the person. Characteristic of Herman's approach is the fact that neither of the two motives is more valued than the other. On the contrary, he states that both motives are essential in the healthy person via flexible cooperation, alternation and complementarity. The two motives, active and recognized in a variety of intrapersonal voices, are in a permanent dialogue with each other, resulting in a pattern of alternating dominance of either one of the motives.

With the dialogical interviewing technique we elaborate on the biographic interview technique of Kelchtermans (1991; 1994; 2006). However, it should be stressed at this point that there is an important difference. Usually with interviews, it is the interviewer who asks the questions and interprets the given answers. In the dialogical biographic interview there are no questions to be answered, but 'elicitors' - related to the past, present and future life of the interviewee - to be dealt with. The interviewer (or 'helper') assists the interviewee to formulate in a succinct way the core of the story that was told as a reaction on the 'elicitor'. In a so called 'valuation', closely related to the concept of 'critical incident' of Kelchtermans, the interviewee phrases important and at the manifest level still remembered incidents. The person concludes on the meaning of certain incidents not by logical reasoning, but by their non-rational and affectively experienced commitment, be it positive or negative. The affectscores are represented in the so called affect matrix. In a cooperative and dialogical process of the interviewer as researcher and the interviewee as co-researcher of the affect matrix, meaning is given to the reactions of the interviewee, from which emerges his or her leading life theme.

The SCM has proved to be a suitable instrument for broad and deep reflection; deep reflection, in contrast with broad reflection, being more than analyzing the course of events. Is broad reflection 
aiming at finding out about cause and effect, deep reflection is directed towards the (re)construction of meaning. In this dialogical process the principal's professional identity, her/his subjective theory on education and its religious components become more articulated in their mutual relationship to the school's identity.

As an example on the relationship between personal and professional identity development of the principal and the identity development of her/his school, we present the case of teacher $\mathrm{C}$. She is a young woman, a daughter of Turkish immigrants, born in the Netherlands and educated as a teacher at an outstanding Protestant teacher training college. Since three years she is teaching at an Islamic school in the central part of the Netherlands. A central position in her life story is given to the following critical incident of a scrimmage during a school excursion. As a child she witnessed the fight of a Dutch guy with one of her teachers. The boy offended the teacher because she was wearing her scarf, shouting at her: "Go back to your own country!". Resulting from this experience, teacher C. says, is her subjective educational theory with the central element of empowerment. "My pupils have to be aware of their background, should know their strength and be prepared to put in a great effort to ensure their position in Dutch society". She elucidates this statement by referring to the Qur'an and the Hadith writing about the obligation to develop personal qualities and ameliorate subjective knowledge. A reference she makes during her lessons too. This could be said to be a characteristic of this Islamic school, since it is not only this teacher, but also her colleagues who stress the importance of empowerment.

What strikes us when we analyze the SCM interviews and the life themes the principals formulated, is the difference between Christian and Islamic schools. In the Christian schools it is not the daily routines that are subject of deliberations of principals as well as teachers, but far more often personal opinions, subjective educational theories and aspects of mutual cooperation. Their personal identity as well as in their professional identity is not so much worded with the help of religious concepts. Secularity seems to have affected the language in which they express their professional identity since their 
wording is imbued with pedagogical and didactic concepts. Strikingly absent in their statements, as compared to the formulations of the colleagues from Islamic schools, is a relationship with the affiliated religious tradition of the school. Lacking seems to be a communal language to express faith related concepts in their commitment to religious aspects of the life theme in their professional identity. Interviewing principals of Islamic schools, we see a clear distinction when they talk about their role as a director, or whether they speak about their professional identity and subjective educational theory for themselves.

Whereas in the language of the principals in Christian schools as well as in Islamic schools embarrassment seems to prevail, teachers of the Islamic schools express their religious affiliation boldly. It is not only the RE teacher who freely speaks about her/his religious beliefs - as might be expected from an RE teacher - during geography lessons as well as in the classroom conversation the teacher refers to Qu'ranic texts or desirable behavior of 'a good muslim' without any hesitation (Bakker \& Ter Avest 2005; Ter Avest 2006).

\section{EXAMPLES OF 'GOOD PRACTICE'}

As we have demonstrated above there seems to be a gap to be bridged between the formal identity and the way teachers shape and create identity in their classroom (Bakker 2004). Before this gap can be bridged, we have to know what is on both sides. Since the formal identity of Christian schools has been extensively researched, in this third method of our triangulated qualitative and explorative research project we take our starting point in self-narratives of teachers. The self-narratives are created by teachers themselves and are the result of an assignment in which they were asked to write down and elaborate a concrete example of 'good practice' in their own school and their own teaching-practice. An example of which they "have the feeling that the identity of the school (as perceived by the teacher) is most optimally expressed". In addition the teacher is asked "to indicate why this narrative is such a good example" (Bakker \& Ter Avest, 2003). Subsequently they were asked to share these stories with colleagues. The 
telling of the stories bridges the gap and crosses boundaries of lack of knowledge of each others life view, inspiration and motivation.

In the chosen example of 'good practice' the teacher/author expresses an important experience, a 'critical incident'. H/she sheds an other light on the experiences, h/she dis-covers the events in such a way that the reader is able to experience the events anew. "Writing, then, relives and reinscribes experience, bringing newly discovered meanings to the reader" (Denzin 2000, 504). To relive and reinscribe experience, to bring newly discovered meanings to the reader, the teacher makes use of key phrases and keywords. Together with the implicitly and explicitly offered interpretations they enable us to write a tentative conclusion about the characteristics of the 'critical incidents'. We presuppose that these characteristics constitute the school's identity.

As an example of the above mentioned processes - out of 428 cases - we present the narrative of one of the teachers who tells about the conversation she had with one of her pupils. With this case we will explore the key sentences and keywords and interpret them, being a so called 'informed reader'.

"It was to one of the girls of my group that I had to bring the message that her results were not good enough to pass to the next group. During the past year I had been able to establish a good relationship with her, and we did discuss the abnormal behavior she displayed as well as her learning disabilities. At the end of the conversation on her poor results she was very emotional, she cried and was worried. We repeatedly talked about the situation and one day she said she felt sad and said she was afraid. Together we walked down the stairs and halfway we sat down. I said to her: 'Whenever I feel sad God is in my mind and I then talk to him. One day God said to me not to worry about what tomorrow might bring'. In reaction to this she hugged me. During the last weeks that she was my pupil she frequently came to me and said: 'Do you remember, miss?' After one more year I again became the teacher of the group she belonged to. She often remembered me of that particular moment and we liked to keep this as a kind of a little secret of our own". 
As in many of the 'examples of good practice' the word relation or relationship is used frequently and can be identified as a key word. In the many stories very often teachers write about a relationship with one of their pupils, sometimes about relationships between their pupils but hardly ever about the relationship with their colleagues. In the above mentioned example characteristic for the relationship seems to be the need (for comfort) from the part of the pupil. The attention of the teacher is drawn to the pupil because of the latter's sadness and anxiety as a result of the experienced threat by the pupil not to be allowed to pass to the next class because of her poor results. The child, in her verbal and/or non-verbal signals, starts the communication with the teacher. Instead of asking the child in what way she usually copes in situations of distress (a need for exploration of her own strength), the teacher interprets the child's anxiety as a need for comfort and reacts to this situation by offering what she thinks the be the child's need. She makes use of her own frame of reference and out of her own biography she digs out her own solution and tells the child in what way she herself used to deal with this kind of situation. With the message 'don't worry about what tomorrow might bring' she conveys an interpretation of the core of the Christian tradition to the child: have your trust upon God. The teacher notices a need from the part of the pupil and offers a solution. Encounter in this way looks like a market place situation of supply and demand: the child is the customer and the teacher has an offer to make. In the above mentioned situation the teacher seems to have done the right thing at the right moment, she showed her sensitivity to the child's needs, and the child seemed to be happy with the teacher's answer and hugged her. In this way she establishes the mutuality of the relationship, of which the hug becomes the symbol in years to come.

In the above case, as in most of the written cases of 'good practice' the encounter is central and relation is a keyword. Mutuality of the relationship shows itself in the reaction of the child, which is positively evaluated by the teacher. The relation is established by a noticed and verbal or non-verbal communicated need of the child to which the teacher responds in offering an 
answer. The child is a person in need, the teacher has something to offer.

Simply and solely the act of writing down such a critical experience shows the strength of consciousness-raising reflection resulting in self awareness concerning to the own part every teachers plays in the construction of the school's identity. The personal trouble of concretizing the school's identity in actual classroom behavior turns out to be a public issue of the whole school community.

"It happened to me"', is the conclusion of one of the teachers after that she had written in a thick description extensively about a situation in which the pupils responded to a complex situation in a very response-able way. The core of the situation to this teacher was 'children taking up their responsibility for each other' for which the opportunity was created by her in an instructive environment. But in the end she has to admit "It happened to me". We might coin this as the transcendent moment in the encounter, which differs from the above mentioned respectful encounter in one important characteristic of encounter, that is in the extent of involvement and commitment with the otherness of the other (Ter Avest \& Bakker, 2006).

\section{DISCUSSION AND RECOMMENDATIONS}

In the narrative approach mostly the focus is on the individual. In our presented approach on $\mathrm{RE}$, however, individual and social or communal perspectives that is multi-faceted narratives were combined dealing with different denominational schools.

The first research method explored the relationship between identity construction and school management. It shows the intertwinement and contradictions between the formal school identity and the lived identity by principals with their team, that is the tensions between the deductive and the inductive modes.

From the second research method we learn that some memories from childhood are everlasting and strong in their influence on actual behavior. We know that emotional memories are encoded and stored very well, and retrieved with great accuracy, as the 'valuation' of principal C. shows. The emotions scored, and presented in the affect-matrix, through 
their correlations pave the way for the emerging of the life theme and its practical consequences in her management style.

Detailed descriptions also characterize the examples of good practice, written down by the teachers that constitute the data of the third research method. With great accuracy the teachers tell about the core aspect of the critical incident that in their view is characteristic for the identity of the school. In their actual behavior teachers concretize this identity. They don't feel committed to the formal identity, but to the identity as 'a living document'.

Out of our triangulation of qualitative research method emerges the image of the principal/teacher being at the centre of the school's identity. It is by the teacher's classroom behavior that the identity of the school is shaped. At the same time it appears that it is the principal and her/his autobiographically rooted management style, that facilitates a certain cohesiveness emerging from the diversity of classroom activities.

From our data we learn that the pictures we took in the classroom of primary schools of teachers in Christian and Islamic schools are remarkable different. In Islamic schools the language of religion and beliefs is used in $R E$ lessons as well in lessons on for example the topic of citizenship. The $\mathrm{RE}$ teacher relates texts from the Qu'ran and Hadith to every day life. In the same way the teacher, talking about the responsibility of how to dress or to respond to provocations of Dutch people towards immigrants, refers to what has been taught in $\mathrm{RE}$ lessons on responsibility of every Muslim towards God. No embarrassment is experienced in relating everyday experiences to God, on the contrary, in a natural way every argument is stressed by stating that 'being a good Muslim' and 'as it says in the Qu'ran' or 'as we know from the Hadith of our Prophet' one should behave in such and such way.

However, more research is needed focusing on the mutuality of the three until now separate lines through which the identity of a school is constructed.

In the introduction we stated that the Netherlands are a secularized society in which the role of institutional religion has gradually decreased during the nineties of the last century. 
However, at the beginning of the twenty-first century the educational system is still organized at the base of denominational dividing lines of earlier years. It is the era that institutional religion is 'out', but it is also the era that informal and unbound religiosity is 'in'. From 'The Atlas of European Value Study' (Halman et al. 2005) we learn that only one third of the Dutch population experiences some affinity with institutionalized religion in some way or an other. As vague as the attitude towards churches are the personal feelings of religiosity. The Dutch term 'Iets-isme' ('Whatever-ism') was coined to describe the way religiosity in the beginning of the twentieth century is shaped.

The American-Dutch historian Kennedy notices a lack of interest in institutionalized religiosity, whereas an increase of personal religiosity finds its way in popsongs and massive turnouts (Kennedy 2005). Our data show a strong influence of the subjective biographical 'critical incidents' on the construction of the school's identity. So, our narrative approach presented here in which multifaceted narratives are combined is fully in line with Kennedy's plea, because we do not neglect the social or communal side by favourizing or overaccentuating the individual side.

Ina ter Avest is senior researcher in Religious Education at the Vrije Universiteit Amsterdam and research lecturer in Denominational School Identity at CHN University at Leeuwarden, the Netherlands. E-mail: kh.ter.avestepsy.vu.nl.

Cok Bakker is professor in Religious Education at the Faculty of Humanities (Sub-Faculty of Theology) at Utrecht University, the Netherlands. E-mail: cbakker@theo.uu.nl.

Siebren Miedema is professor in Educational Foundations and professor in Religious Education at the Vrije Universiteit Amsterdam, the Netherlands. E-mail: s.miedemalpsy.vu.nl.

\section{REFERENCES}

Bakker, C. 2004. Demasqué van het christelijk onderwijs? Over onzin en zin van een adjectief [Unmasking Christian education. On sense and nonsense of an adjective]. Utrecht: Universiteit 
Utrecht .

Bakker, C. \& S. Miedema. 2006. Dimensions of school identity formation. Research about and with principals of Dutch elementary schools. In: C. Bakker \& $\mathrm{H}-\mathrm{G}$. Heimbrock (Eds.). Researching $R E$ Teachers. RE Teachers as Researchers. Waxmann: Münster/New York/München/Berlin (in press).

Bakker, C. and I. ter Avest. 2005. School ethics and its religious dimension. Scriptura 89: 350-362.

Bosma, H.A. and T.L.G. Graafsma. 1982. De ontwikkeling van identiteit in de adolescentie. [The development of identity in adolescence]. Nijmegen: Dekker \& van der Vegt.

Breeuwsma, G. 1994. De constructie van de levensloop [The construction of lifespan]. Amsterdam: Boom/Open Universiteit.

Bruner, J. 1996. The Culture of Education. Cambridge/ London, U.K.: Harvard University Press.

Carrithers, M. 1992. Why Humans have Cultures. Explaining Anthropology and Social Diversity. Oxford/New York: Oxford University Press.

Denzin, N.K. 2000. Interpretive Interactionism. London/ New Delhi: Sage Publications.

De Wolff, A.J.C. 2000. Typisch christelijk? Een onderzoek naar de identiteit van een christelijke school en haar vormgeving [Typical Christian?]. Kampen: Kok.

De Wolff, A.J.C., D.J. de Ruyter \& S. Miedema. 2003. Being a Christian school in the Netherlands: an analysis of 'identity' conceptions and their practical implications. Journal of Belief \& Values 24 (2) : 207-217.

Freeman, M. 1991. Rewriting the Self: Development as Moral Practice. New Directions for Child Development 54: 83-102.

Halman, L., R. Luijkx and M. van Zundert (Eds.) 2005. Atlas of European values. European values studies. Tilburg: University Press. 
Hermans, H.J.M. and E. Hermans-Jansen. 1995. SelfNarratives. The Construction of Meaning in Psychotherapy. New York: Guilford Press.

Hofstede, G. 2002. Allemal andersdenkenden. Omgaan met cultuurverschillen [All thinking differently. Dealing with differences]. Amsterdam: Uitgeverij Contact Amsterdam.

Kelchermans, G. 1991. De professionele ontwikkeling van leerkrachten vanuit het biografisch perspectief [The professional development of teachers from a biographical perspective]. Nederlands Tijdschrift voor Opvoeding, Vorming en Onderwijs 7 (3).

Kelchtermans G. 1994 . De professionele
ontwikkeling van leerkrachten basisonderwijs
vanuit het biografisch perspectief [The
professional development of elementary school
teachers from a biographical perspective].
Leuven: Universitaire Pers.

Kelchtermans, G. 2006. Capturing the muldidimensionality of teacher professionalism: Broad and Deep Reflection. In: Postgraduate Programs as Platform: An Interactive and Researchled Approach. Dordrecht: Sense Publishers (in press).

Kennedy, J.C. 2005. Recent Dutch religious history and the limits of secularization. In: E. Sengers (Ed.). The Dutch and their Gods. Secularization and transformation of religion in the Netherlands since 1950 (pp. 27-42). Hilversum: Verloren.

Langeveld, J. 1956. Kind en religie. Enige vragen voorafgaande aan een 'godsdienst-pedagogiek'. Utrecht: Bijleveld.

Luther, H. 1992. Religion und Alltag. Bausteine zu einer Praktischen Theologie des Subjekts. Stuttgart: Radius Verlag.

Hardy, J. 2002. Levinas and Environmental Education. Educational Philosophy and Theory 34 (4).

Morgan, G. 1992. Beelden van organisaties [Images 
of organizations]. Schiedam: Scriptum Books.

Schein E. 2001. De bedrijfscultuur als ziel van de onderneming [The corporate Culture Survival Guide, Sense and Nonsense About Culture Change]. Schiedam: Scriptum Management.

Taylor, C. 1989. Sources of the Self. The Making of Modern Identity. Cambridge, M.A.: Harvard University Press.

Taylor, C. 1991. The Ethics of Authenticity. Cambridge, M.A.: Harvard University Press.

Ter Avest, I. 2006 Contrasting colors. In: C. Bakker \& $\mathrm{H}-\mathrm{G}$. Heimbrock (Eds.). Researching RE Teachers. RE Teachers as Researchers. Waxmann: Münster/New York/München/Berlin (in press).

Ter Avest, I. and C. Bakker. 2006. School identity, a living document. Presentation at the fourth International Conference of the Dialogical Self, Braga, Portugal. 